F Ali, R Spendiff. Radiology Department, Colchester Hospital University Foundation Trust, Colchester, UK

Background The first radiological investigation in children presenting with suspected non-accidental injury is often the skeletal survey. The purpose of a skeletal survey is to provide a standard series of radiographic images that will visualise the entire skeleton. The Royal College of Radiologists in collaboration with the Royal College of Paediatrics and Child Health has published Standards for Radiological Investigations of Suspected Non-accidental Injury. It includes imaging of ten sets of body parts. National target is $100 \%$.

Methods It was a retrospective study. Local practice was checked against National standards. All cases with suspected non-accidental injury under the age of 2 presented within last 3 years were included in this study. Case notes and radiology system was reviewed to collect data. Information was recorded on Proforma $\&$ analysed.

Results Total number of children presented during this time period were 27 . Out of which 17 were males and 10 were females. Only $18.5 \%$ had complete set of $\mathrm{x}$ rays as a part of skeletal survey, which is far less than national recommended standards. Skull, Ribs and Spine were missed in more than $30 \%$ of cases. Results were discussed locally and causes were identified. Changes were made to practice including all cases should be discussed in multidisciplinary meetings, reports counter signed by pediatric radiologist and awareness of national guidelines.

Conclusion Adherence to protocols in this context is currently poor. Non-accidental injury has medico-legal and children safety aspects. Skeletal survey is an important tool to diagnose suspects accurately which should be used wisely.

\section{MATERNAL AGE, HISTORY OF MIGRATION AND INCIDENCE OF INFANTILE HYPERTROPHIC PYLORIC STENOSIS IN GERMANY IN 2000-2008}

doi:10.1136/archdischild-2012-302724.0982

1J de Laffolie, ${ }^{2} S$ Turial, ${ }^{2} \mathrm{~F}$ Schier. 'General Pediatrics and Neonatology, University of Gießen, Gießen; '2Department of Pediatric Surgery, University of Mainz, Mainz, Germany

Background The incidence of infantile hypertrophic pyloric stenosis (IHPS) is highly variable over time and geographic regions. A decline in IHPS incidence was recently reported in Sweden, the US, Denmark, and Scotland and in Germany.

Aim In further evaluation of our previous epidemiological data, we collected data on maternal age and history of migration in mothers from the regional administrations. We examined correlations between these factors and IHPS incidence.

Methods Data were extracted from the public report of Health (Gesundheitsberichterstattung des Bundes) and population data from federal state governments. We collected the numbers of IHPS (International Statistical Classification of Diseases and Related Health Problems, 10th revision [ICD-10], code 40.0), SIDS (ICD-10, R95), and live births (LB; male/female) in each federal state for 2000-2008. Further data were collected from federal state administrations on age of mothers at birth of first child and history of migration in \% of all mothers at first birth.

Results The IHPS Incidence declined in Germany from 2000 (3.2086/1000LB [range 1.67-5.33]) to 2008 (2.0175/1000LB [1.74$3.72] ; p=0.005)$. The recorded incidence was highly variable in different federal states and over time. Negative correlation between percentage of mothers with history of migration and maternal age at first birth on the one side and IHPS incidence in the different regions and years was significant.
Conclusion The IHPS incidence declined by about 38\% nationwide. The wide variation in time and different regions is significantly correlated with maternal age and history of migration.

\section{EPIDEMIOLOGICAL PROFILE OF THE SERVICE PLAN FOR THE HIGH RISK IN MATERNAL-FETAL PUBLIC TEACHING HOSPITAL}

doi:10.1136/archdischild-2012-302724.0983

'A Veiga, ${ }^{2} \mathrm{EQ}$ Veiga, ${ }^{3} \mathrm{MCB}$ Soares, ${ }^{2} \mathrm{NV}$ Moliterno, ${ }^{2} \mathrm{SA}$ Nogueira, ${ }^{2} \mathrm{FM}$ Moliterno, ${ }^{2} \mathrm{SS}$ Cordeiro, ${ }^{4}$ Cordebel, ${ }^{4}$ A Siqueira, ${ }^{4}$ RJ Silva. ${ }^{1}$ Paediatrics and Neonatology; ${ }^{2}$ Faculdade de Medicina de Petrópolis; ${ }^{3}$ Paediatrics, Faculdade de Medicina de Petrópolis; ${ }^{4}$ Hospital Alcides Carneiro/FMP, Petrópolis, Brazil

Background and objective To know the epidemiological profile of health services maternal and child care is fundamental importance for the development of quality indicators that contribute to the quality of care for both mother and child. This study aim was to identify the epidemiological profile of the mother and the fetus seen at maternal and child public service only reference in the mountainous region of the State of Rio de Janeiro, Brazil.

Methods Cross sectional study of deliveries in the period from January to June 2011. Variables analyzed: maternal age, gestational age, parity, delivery type, sex, anthropometry and destination of the conceptus.

Results During the study period there were 781 deliveries, $45.3 \%$ of cesareanas. As the fetus to term and $65.2 \%$ frequency of gender equitable. Maternal age was 25.6 years and average parity of 2.5 with $32 \%$ primiparous pregnancies. Mean weight, height, head circumference, thoracic, abdominal and Apgar scores were 3019g, 47.5 $\mathrm{cm}, 33.6 \mathrm{~cm}, 32.5 \mathrm{~cm}, 31 \mathrm{~cm}, 8$ and 9 respectively. Of the total live births, $0.6 \%$ evolved to death in the delivery room, $12 \%$ referred to the neonatal ICU and of these $61.57 \%$ for prematurity.

Conclusion We are facing a referenced service to high-risk pregnancy and cesarean rates of prematurity are above the level recommended by the Ministry of Health as an ideal, what leads us to reflect on the need for planning actions to be implemented with goal of greater control and quality of care offered to this same population.

\section{POPULATION-BASED STUDY TO EVALUATE THE NEONATAL MORBIDITY AND MORTALITY IN MATERNAL DIABETES}

doi:10.1136/archdischild-2012-302724.0984

${ }^{1} \mathrm{~A}$ Lange, ${ }^{2 \mathrm{R}}$ Spoo, ${ }^{3 \mathrm{R}}$ Thyrian, ${ }^{3} \mathrm{~W}$ Hoffmann, ${ }^{4} \mathrm{H}$ Lode, ${ }^{2} \mathrm{M}$ Heckmann. ${ }^{\top}$ Neonatology and Intensiv Care, University of Greifswald; ${ }^{2}$ Neonatology and Pediatric Intensive Care, University Children's Hospital; ${ }^{3}$ Community Medicine, University of Greifswald ${ }^{4}$ Haematology and Oncology, University Children's Hospital, Greifswald, Germany

Aim The aim of the study is to determine any connections between maternal diabetes and the pregnancy outcome of mothers and newborns.

Methods From 03/2003 to $11 / 2008$ in local and university hospitals in Northeast Pomerania, Germany a total of $n=4593$ mothers and their children were used as a prospective population-based birth cohort. The objective of the survey of newborns in Pomerania ( $\mathrm{SNiP}$ ) is to evaluate the negative pregnancy outcome, morbidity and mortality in diabetes affected pregnant woman. A comparison of glucose-intolerance affected childbearing mothers $(n=243)$ identified by oral glucose tolerance test and non-diabetic mothers $(\mathrm{n}=4350)$ were conducted.

Results The prevalence of maternal glucose-intolerance is $5.3 \%$, Comorbidity of maternal diabetes is more prevelant with higher age, greater number of previous pregnancies (parity) and those who are overweight (relative risk 1.97). Macrosomi $(\mathrm{OR}=2.28)$ and reduced gestational age are identified as a fetal risk factors. As a maternal risk factor is considered positive vaginal infection $(O R=1.97)$. As a 
negative outcome a higher rate of Cesarean section, instrumental delivery $(\mathrm{OR}=1.96)$ and pathologic final delivery positions $(15.3 \%$ non-diabetes $/ 9.3 \%$ diabetes) can be observed. This all leads to a four times higher odds ratio of post-partus hospitalization $(\mathrm{OR}=3.70)$ and mandatory pre-partus therapy $(\mathrm{OR}=4.78)$ of the diabetes affected group.

Conclusions Newborns of mothers with gestational diabetes demonstrate a fetopathia diabetica with makrosomi and immaturity which leads to higher rate of birth complications and postpartus hospitalisation of almost every second newborn. An increased risk for mothers and their children exists in case of gestational diabetes.

\section{MALE VERY-LOW-BIRTH-WEIGHT AND VERY-LOW- GESTATIONAL-AGE INFANTS HAVE ADVERSE PERINATAL OUTCOMES}

doi:10.1136/archdischild-2012-302724.0985

${ }^{1} \mathrm{~A}$ Valls-i-Soler, ${ }^{2} \mathrm{~A}$ Azpeitia, European Neonatal Network (EuroNeoNet). ${ }^{1}$ Cruces University Hospital; ${ }^{2}$ BIOEF, Barakaldo, Spain

Background It's generally accepted that male Very Low Birth Weight (VLBW)/Very Low Gestational Age (VLGA) infants have a higher neonatal mortality rate (NMR), and this has been questioned recently (Arch Dis Child Fetal-Neonatal Ed. 2009; 94:F140-3).

Aim To determine if male gender has an adverse effect on NMR and early morbidity in VLBW/VLGA infants.

Methods Perinatal risk/protective factors, early neonatal complications and NMR were compared between male and female VLBW/ VLGA infants admitted from 2006 to 2010 in 174 EuroNeoNet NICUs from 17 European countries $(\mathrm{N}=28,035)$. Independent comparisons using non-parametric tests and logistic regression models were performed to predict adjusted NMR. Crude and adjusted odds ratios (OR) were used to determine perinatal and early neonatal associations.

Results Male infants (52.3\%) had a lower GA and higher BW than females. Crude NMR was higher in males (14 vs. $11.6 \%$; OR=1.24 95\%CI: (1.16-1.33)) as were most perinatal and early neonatal risk factors (vaginal delivery, low Apgar scores, resuscitation, RDS and need for surfactant therapy and early-onset sepsis), as well as major adverse neonatal outcomes (pneumothorax, late-onset sepsis, BPD, $\mathrm{IVH}_{3-4}, \mathrm{PVL}$ and $\mathrm{ROP}_{3-4}$ ). These differences in NMR and complications remained after adjusting for GA and/or BW alone and by perinatal differentiating factors for gender: BW, GA, 1-min Apgar score and multiple pregnancy (NM: OR=1.32 95\%CI: 1.21-1.44).

Conclusion Male infants of VLBW/VLGA have a higher adjusted NMR and an increased rate of adverse neonatal outcomes.

Acknowledgements We thank patients and NICUs participating NICU's. EuroNeoNet is supported by the DGSANCO (EuroNeoStat project No 2008/1311).

\section{A COMPARISON BETWEEN EFFECTS OF VAGINAL MISOPROSTOL AND OXYTOCIN IN SUCCESSFUL INDUCTION OF LABOR: A DOUBLE BLIND CLINICAL TRIAL}

doi:10.1136/archdischild-2012-302724.0986

M Bakhtiyari. Tehran University of Medical Sciences, Tehran, Iran

Aim and Background: Labor induction for Prepare the cervix to active phase of labor, is now one of the most common methods in the field of Obstetrics and Gynecology. This study was conducted to compare the effects of misoprostol and oxytocin in BoAli Hospital, Tehran in 2011.

Method This study was a double-blind clinical trial by recruitments of 60 primiparous women that has been referred to BoAli hospital in Tehran in 2011. Individuals were divided into two groups by random allocation. For induction of labor, misoprostol and oxytocin were prescribe in individuals who candidate for pregnancy termination by four hours intervals. For Analysis of data, t test, analysis of variance with repeated measurements, linear regression and descriptive statistics were used.

Results Mean age and standard deviation in intervention group was $24.07 \pm 3.96$ and in control group equal to $24.13 \pm 3.97$. Kind of treatment variable, cause of admission and hypertension history shown a significant association with increased or decreased time to achieve regular and suitable contractions for delivery $(p<0.05)$. Results of $t$ test in two groups of intervention and control shown that until three hours after receive Assigned treatment, there was no statistical significancy between two groups of study, But then we are clearly seeing the better impact of misoprostol drug in the intervention group ( $\mathrm{p}=0.014)$.

Conclusion Using misoprostol in labor induction in order to reducing the Time to reach the short and effective contraction is more effective Instead of oxytocin and it can be a good alternative.

\section{EMIPEDIOLOGY AND MORBIDITY OF LATE PRETERM NEONATES IN CORRELATION WITH MATERNAL RISK FACTORS IN HESSEN, GERMANY}

doi:10.1136/archdischild-2012-302724.0987

'D Faas, 'M Vajz, ${ }^{2} \mathrm{U}$ Hennewig, ${ }^{3} \mathrm{~B}$ Misselwitz, ${ }^{4} \mathrm{~F}$ Oehmke, ${ }^{5} \mathrm{M}$ Heckmann. ${ }^{1}$ General Pediatrics and Neonatology, Justus-Liebig-University Giessen, Giessen; 2Pediatric Hematology and Oncology, Johannes Gutenberg University of Mainz, Mainz; ${ }^{3}$ nstitut for Quality Assurance Hessen, Eschborn; " Department of Obstetrics and Gynecology, Justus-Liebig-University Giessen, Giessen; ${ }^{5}$ Neonatology and Pediatric Intensive Care, Ernst Moritz Arndt University Greifswald, Greifswald, Germany

Short and long term morbidity in late preterm neonates (LP) and their correlation to maternal risk factors are relevant as shown in multiple studies in North America and European countries. Epidemiological studies showed an increase in LP birth over time. Corresponding data for Germany have not yet been published. Our goal was to evaluate the epidemiology of LP over a 7 year period and the correlation to potential maternal risk factors in Hessen, Germany.

Data was collected from the perinatal und neonatal quality assurance in Hessen form 2001 to 2007. For some calculations the two data sets were merged. Overall the data sets of 360.000 births and 44.000 neonatal hospitalizations were available, which is about $7.5 \%$ of all births during that period in Germany.

There is no increase in LP births from 2001 to 2007 in Hessen. Neonatal short term morbidity of LP is within the expected range and significantly higher than in term neonates. The following maternal risk factors were more predominant in LP: placental insufficiency, gestational diabetes, obesity, arterial hypertension, artificial reproduction techniques, caesarian section in previous pregnancy, ethnic background and multiple births. Maternal morbidity has an influence on the short term morbidity of LP.

There has been no increase in late preterm births in Hessen Germany 2001-2007. Several maternal risk factors for late preterm births can be identified. These results could be used to optimize management of mothers at risk to reduce the number of late preterm births and neonatal morbidity.

\section{EFFECTS OF IRON SUPPLEMENTATION OF LOW BIRTH WEIGHT INFANTS ON COGNITION AND BEHAVIOR AT 3 YEARS}

doi:10.1136/archdischild-2012-302724.0988

'S Berglund, ${ }^{2 B}$ Westrup, ${ }^{3} \mathrm{~B}$ Hägglöf, ${ }^{1} \mathrm{O}$ Hernell, ${ }^{1} \mathrm{M}$ Domellöf. ${ }^{1}$ Clinical Science, Pediatrics, Umeå University, Umeå; ${ }^{2}$ Women and Child Health, Neonatology, Karolinska Institute, Stockholm: ${ }^{3}$ Clinical Sciences, Child and Adolescent Psychiatry, Umeå University, Umeå, Sweden 